\title{
Regional Wealth as a Universal Criterion for Spatial Development of Territories
}

\author{
Vladislav Anichin \\ Department of Economics \\ Belgorod State Agricultural University named after V. Gorin \\ Belgorod, Russia \\ vladislavanichin@ rambler.ru \\ Yury Kitaev \\ Department of Economics \\ Belgorod State Agricultural University named after V. Gorin \\ Belgorod, Russia \\ yurgenk@inbox.ru
}

\author{
Natalia Smurova \\ Department of Economics \\ Belgorod State Agricultural University named after V. Gorin \\ Belgorod, Russia \\ smurovanat@yandex.ru \\ Alina Dobrunova \\ Department of Economics \\ Belgorod State Agricultural University named after V. Gorin \\ Belgorod, Russia \\ dobrunova@mail.ru
}

\begin{abstract}
The spatial development of the territory is subject to the management of the responsible public authority. Voters expect positive changes in the economic, social and environmental spheres of the territories in which they live, work and spend their leisure time. The activities of the regional authorities are also under the control of the federal center. The variety of directions of spatial development gives rise to a variety of indicators used and proposed to assess the effectiveness of government bodies. The large number of performance indicators makes it difficult to monitor spatial development. There is an objective need to use a limited number of estimated indicators that adequately reflect changes in territorial socio-ecological and economic systems. One of these indicators can be the size of regional wealth. Nothing characterizes the changes in the level of development of the region as an increase in regional wealth in general and in the context of the main components: human, natural and physical capital. However, methodological problems do not yet allow building an integral indicator of regional wealth. The main obstacle is the difficulty in assessing natural capital.
\end{abstract}

Keywords-spatial development, region, regional wealth, integral indicator, natural capital.

\section{INTRODUCTION}

Spatial development of the territory occurs through positive changes in the economic, social and environmental spheres. In the economic sphere, such changes include, an increase in the number of subjects and objects of economic activity, an increase in the efficiency of the use of production resources, an improvement in the distribution of productive forces. In the social sphere, the spatial development of the territory is embodied in the development of social infrastructure, raising the cultural level of the population, strengthening the systems of medicine and education, creating and developing progressive social institutions. The result is an improvement in the quality of life and an increase in the population. In the ecological sphere, the spatial development of the territory is expressed in environmental protection, including the reproduction of natural resources and natural and anthropogenic objects.

P.A. Minakir and A.N. Demyanenko, analyzing the content of the terms "territory" and "space", note that "territory" describes economic phenomena and processes in the geographical aspect, and "space" - the space of economic agents and the relationship between them [1] In this interpretation, the spatial development of the territory is the expansion of the scope of activity and interaction of economic agents within the geographical boundaries of the region.

Spatial development serves the interests of the region's population in all spheres of life and activity. Therefore, firstly, spatial development must be within the competence of the public authority of the respective territory; second, the results of spatial development are measurable; thirdly, the assessment of the performance of public authorities should be carried out based on their competence in the regulation of spatial development and the results achieved.

In this regard, an objective need arises for an effective criterion for the spatial development of the region. The effectiveness of the criterion in this case is characterized by the following features: 1) coverage of all aspects of spatial development; 2) adequacy to the competences of the authorities; 3) simplicity and correctness of computational procedures.

The most appropriate indicator for the role of such a criterion is regional wealth. It is human nature to control property and territory. In this respect, the indicator of 
regional wealth, like no other, will reflect the state of regional development.

\section{METHODS}

General scientific methods of analysis and synthesis were used as research tools, as well as specific research methods such as: monographic method, abstract-logical, calculation-graphic, economic-statistical, comparative financial-economic analysis, etc.

\section{MAIN PART}

A number of authors draw attention to the advisability of using the indicator of national (regional) wealth in the practice of managing the national economy and regional development. The growth in regional wealth is opposed to the GRP indicator, and the growth in national wealth is seen as an indicator that should replace GDP. This is the conclusion made by foreign and Russian researchers.

The World Bank experts note in particular: "Although a macroeconomic indicator such as GDP provides an important measure of economic progress, it measures only income and production and does not reflect changes in the underlying asset base. Used alone, GDP may provide misleading signals about the health of an economy. It does not reflect depreciation and depletion of assets, whether investment and accumulation of wealth are keeping pace with population growth, or whether the mix of assets is consistent with a country's development goals"[2].

M.V. Ledeneva also considers the growth rate of national wealth as an alternative to the gross domestic product. She divides the aggregate increase in national wealth into the following components: human capital; natural resources; reproducible capital; the state of the natural environment [3].

V.V. Pechatkin substantiates the need to use the category "regional wealth" in the practice of territorial administration and proposes a toolkit for assessing regional wealth tested in the Republic of Bashkortostan, taking into account the parameters of environmental rent and human capital. Moreover, V.V. Pechatkin focuses his research on measures to increase the efficiency of using individual elements of regional wealth [4].

I.S. Bukin, A.V. Odintsov and P.A. Orekhovsky note the prevalence of flow indicators, which are currently used to assess the size of the economy and the efficiency of its functioning. At the same time, the key category of the economy is capital, usually described as an indicator of stock. On a national scale, capital represents national wealth, and on a regional scale, regional wealth. These authors propose to use the ratio of value added and national wealth to assess the efficiency of the economy. They note that the existing spatial structure of the Russian economy is characterized by contradictions between the return of regional wealth and its distribution. The richest regions often show a return on wealth significantly below the average Russian level [5]. In our opinion, one should distinguish between general regional wealth and regional wealth involved in the market turnover. First of all, this refers to natural capital, in the structure of which the share of those not involved in the market turnover can be significant. Accordingly, the level of return to regional wealth should be defined as the ratio of value added to the wealth involved in the market turnover. The second possible way to measure the return of regional wealth is to calculate the ratio of the sum of the increase in regional wealth and value added to the total regional wealth.

In publications devoted to assessing the effectiveness of public authorities, it is widely believed that the quality of regional governance can be judged by the level of investment attractiveness of the region, the level of competitiveness of the region and other similar surrogate indicators. On this occasion I.S. Bukin, A.V. Odintsov and P.A. Orekhovsky rightly note that the focus on the ratings of the investment attractiveness of the regions misleads the economic authorities of Russia [5].

Until sometime, the use of ratings of investment attractiveness of regions took place in the practice of public administration. So, among the indicators for assessing the effectiveness of the executive authorities of the constituent entities of the Russian Federation, approved by the Decree of the President of the Russian Federation of November 14, 2017 No. 548, was the "Integral index of the constituent entity of the Russian Federation in the national rating of the state of the investment climate in the constituent entities of the Russian Federation" [6]. In the current list of indicators, approved by the Decree of the President of the Russian Federation of April 25, 2019 N 193 [7], such an indicator is absent, and the total number of indicators has decreased from 24 to 15 .

Obviously, only methodological difficulties do not allow the inclusion of regional wealth and its derivatives in the list of indicators for assessing the effectiveness of public authorities.

N.A. Latushko highlights the following problems that arise when assessing regional wealth: the lack of a generally accepted system of definitions of regional wealth; incomplete and imperfect regional statistical information; insufficient evidence base of approaches used to measure the components of regional wealth, which creates ambiguity in assessing the desired result. There are discrepancies in the characteristics of the structure of regional wealth and its individual components, including natural capital and physical capital. Methodological difficulties in assessing the quality of human capital have not yet been fully overcome [8].

O. G. Vasilyeva, investigating the problems of assessing natural resources in the Russian Federation, notes quite common cases of inconsistency between the territories where natural rent is created and the territories where this rent belongs. These discrepancies are due to the practice of accounting for information used by state statistics bodies in relation to the activities of commercial organizations that have divisional divisions in some regions and head offices with legal addresses in other regions. In addition, a significant part of the natural rent created in the Russian regions during the development of deposits and mining is withdrawn by the tax authorities and sent to the Federal budget [9]. In the end, some of these funds are returned to the regions in the form of grants and inter-budget transfers. 
However, this does not negate the fact that regional authorities are limited in their ability to fill regional budgets with rental income from mining, despite the fact that mining is usually associated with a significant burden on the region's ecosystem. This feature, in our opinion, greatly simplifies the assessment of regional wealth in terms of natural capital. It is important to ensure the adequacy of the assessment of the natural capital of the region and the legal personality of the region due to the fact that there is a differentiation of the rights to use natural resources between the federal center and the regions. Regional wealth in the system of regional spatial development management should be considered and evaluated as a set of physical, human and natural capital, which is subject to the legal personality of the region and its residents [10].
It should be noted that the problem of assessing natural capital has not yet been fully resolved. We have only intentions and attempts to solve it [11, 12, 13]. Natural capital is too diverse, too many of its components are not explicitly involved in the market turnover to be measured in value terms. As a result, it has not yet been possible to form an integral indicator of regional wealth, including human, physical and natural capital.

In the Russian practice of managing the spatial development of territories, there is an assessment of individual parameters of regional wealth, presented in the list of indicators from the Decree of the President of the Russian Federation (Fig. 1).

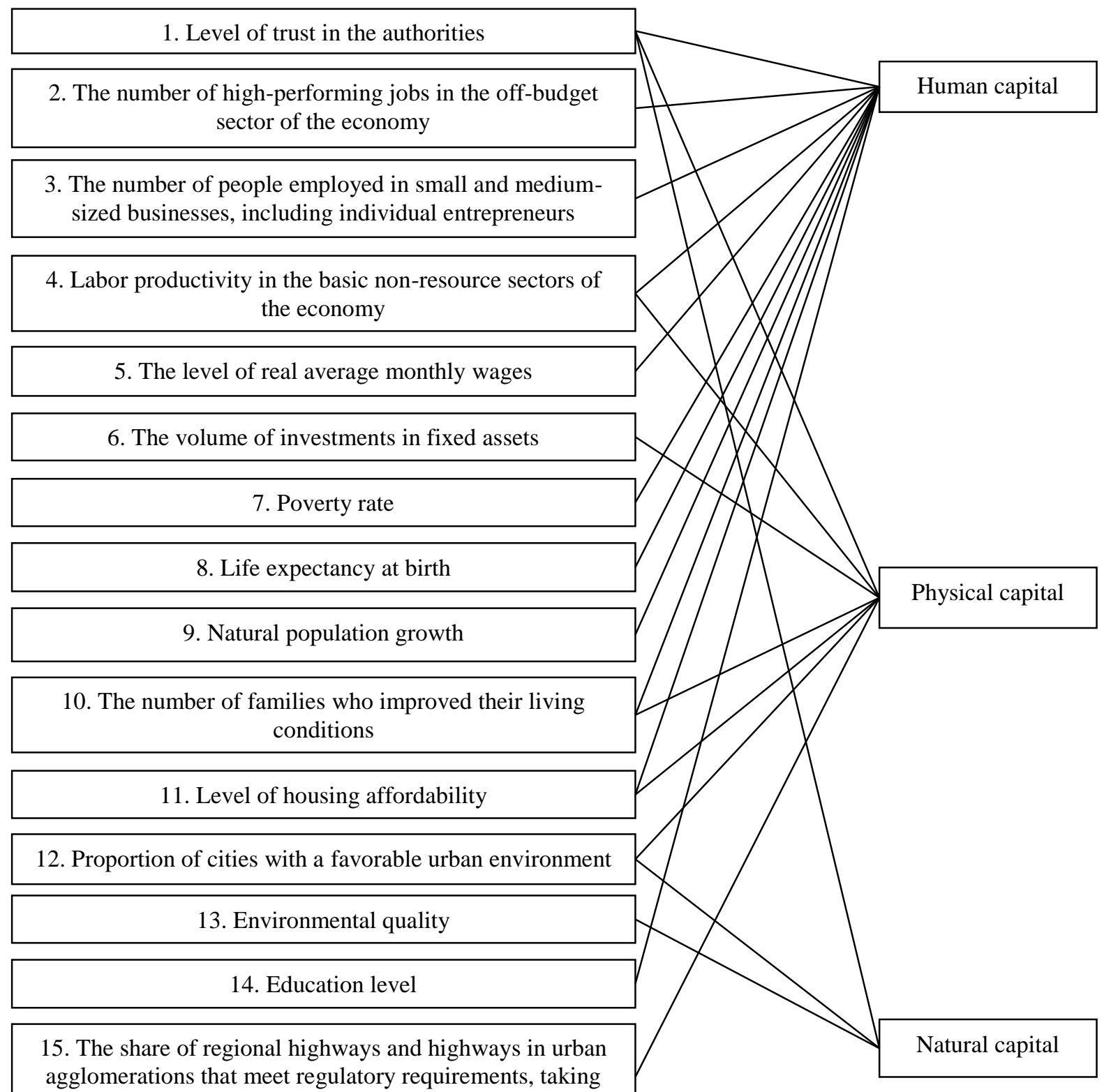

into account congestion

Fig.1. Relationship of 15 official indicators of assessing the public power of Russian regions with the state of regional wealth 
Official estimates record, first of all, changes in the composition of human capital (11 indicators out of 15). 7 indicators reflect changes in the state of physical capital, and only 3 - in the state of natural capital. Some of the indicators characterize changes in the state of two or even three components of regional wealth.

Nothing characterizes the changes in the level of development of the region as an increase in regional wealth in general and in the context of the main components: human, natural and physical capital. In order to build an integral indicator of regional wealth, it is necessary, first of all, to determine the basis for comparing its components. For fixed assets, which represent the majority of physical capital, the residual value should be the base estimate.

A similar approach should be applied to human capital. Its implementation lies in the fact that the amount of discounted labor income is determined for the period of the expected duration of employment. For example, men in their 20 s are expected to have a working life of 50 years, and for men in their 30s it is 10 years less. This approach was implemented in [14]. At the same time, the annual discount rate was conventionally adopted at the level of $\boldsymbol{i}=0.1$. Meanwhile, the question inevitably arises of how the discount rate should be determined. If the integral indicator of regional wealth is the sum of the residual value of physical capital, on the one hand, and discounted income from the use of human and natural capital, on the other hand, then the structure of regional wealth will depend on the discount rate.

V.V. Samoylenko used the social discount rate when calculating the cost of water bio resources, which, according to his estimates, was $3.08 \%$ on average in Russia for 20142018 [15]. Despite the fact that a clear algorithm for determining the social discount rate has not been described in the literature, and the very idea of this indicator has been criticized, for example, in [16], we believe that the standard discount rate is necessary to calculate regional wealth. In our calculations of the regional wealth of the Belgorod region, the discount rate is taken at $4 \%$. It is used to assess the value of the human capital of workers employed in organizations in the region.

Over time, new data on the components of regional and national wealth become publicly available. The regional bodies of the Federal Service for Registration, Cadastre and Cartography of the Russian Federation have carried out work to assess the cadastral value of lands for various purposes. Currently, there is objective information that makes it possible to assess the following components of regional wealth: the residual value of fixed assets, the value of human capital and the cadastral value of land. The results of assessing the regional wealth of the Belgorod region are presented in the table 1 .

The largest share of the regional wealth of the Belgorod region available for measurement is occupied by human capital. The value of human capital exceeds the aggregate size of other components of regional wealth.

As methodological problems are overcome, the indicator of regional wealth will become the main criterion for spatial development. The prerequisites for this are, first of all, the visibility and universality of the indicator. The universality of regional wealth as a criterion for spatial development is due to the following circumstances. First, regional wealth represents all aspects of regional development in their unity and interdependence. It is unlikely that regional wealth will grow only at the expense of one of its components. Wasteful use of natural capital may cause an increase in physical capital, but the total amount of wealth will not increase. Secondly, regional wealth characterizes the integral result of the spatial development of the region. This allows for a concise assessment of both the activities of regional authorities and the overall spatial development of the territory. At the same time, the presence of an integral indicator does not exclude the possibility of a detailed analysis of the components of regional wealth and analysis of structural changes. Third, the size and state of regional wealth reflect the development potential of the territory, since the combination of human capital, physical capital and natural capital is the most important factor in the further development of the region. Therefore, information about the size and structure of regional wealth is suitable not only for summarizing the spatial development of regions, but also for planning and developing (adjusting) regional policies.

TABLE I. Assessment of the Regional Wealth of the BELGOROD REGION IN 2018

\begin{tabular}{|c|c|c|}
\hline Components of regional wealth & $\begin{array}{c}\text { RUB } \\
\text { million }\end{array}$ & $\begin{array}{c}\text { in\% to the } \\
\text { total }\end{array}$ \\
\hline $\begin{array}{c}\text { Residual value of fixed assets at the } \\
\text { end of the year }\end{array}$ & 790099 & 13.0 \\
\hline $\begin{array}{c}\text { Human capital cost } \\
\text { Cadastral value of agricultural land }\end{array}$ & 27922574 & 80,8 \\
\hline $\begin{array}{c}\text { The cadastral value of land for } \\
\text { industrial and special purposes }\end{array}$ & 98816 & 4.6 \\
\hline $\begin{array}{c}\text { The cadastral value of lands of } \\
\text { water Fund }\end{array}$ & 4 & 0,0 \\
\hline $\begin{array}{c}\text { The cadastral value of lands of } \\
\text { forest Fund }\end{array}$ & 884 & 0,0 \\
\hline Subtotal & 6090593 & 100 \\
\hline
\end{tabular}

If we consider regional wealth as a factor in the spatial development of the region, the question naturally arises as to how to evaluate the effectiveness of this factor. In the literature review above, we pointed out two possible ways to construct a regional wealth performance indicator. The first option involves calculating the ratio of value added to the value of regional wealth involved in market turnover. The second option takes into account the change in the total value of regional wealth and is reduced to applying the following formula.

$$
E R W=(\Delta R W+V A) / R W,
$$

where $E R W$ - indicator of the efficiency of using regional wealth, $\% ; \Delta R W$ - growth of regional wealth for the reporting year, RUB million; $V A$ - value added for the reporting year, RUB million; $R W$ - regional wealth at the beginning of the reporting year, RUB million.

Regional wealth, its preservation and multiplication, as well as the added value created by the residents of the region, 
are important results of the spatial development of the region. At the same time, it is possible that part of the added value will be obtained at the expense of the value of regional wealth. Therefore, the indicator of the effectiveness of the use of regional wealth should take into account not only the ratio of value added and regional wealth, but also changes in the value of regional wealth [17].

The visibility and universality of the indicator "regional wealth" as a criterion for spatial development create prerequisites for using this indicator in the distribution of subsidies (grants) between the subjects of the Russian Federation in the form of inter-budget transfers for the results achieved. Currently, rather cumbersome rules for allocating grants are applied, taking into account changes in the level of 15 indicators presented in figure 1 .

We suggest using information about changes in regional wealth as a basis for allocating subsidies. Grants should be provided in three categories: 1) for the achieved per capita level of regional wealth in terms of the aggregate of physical capital and human capital; 2) for a positive absolute increase in regional wealth; 3) for a positive relative increase in regional wealth.

If there are no special priorities for spatial development, the total amount of subsidies (D) provided to appropriate Federal law on the Federal budget to stimulate regional development, should be divided into three equal parts:

$$
D=D 1+D 2+D 3,
$$

where $D 1$ - the amount of subsidies to the constituent entities of the Russian Federation for the achieved level of regional per capita wealth in terms of aggregate physical capital and human capital; D2 - the amount of subsidies to the subjects of the Russian Federation for a positive absolute increase in regional wealth; $D 3$ - the amount of subsidies to the subjects of the Russian Federation for a positive relative increase in regional wealth.

The grantee for the achieved per capita level of regional wealth should be considered any subject of the Russian Federation, which has this indicator higher than the average for Russia. The per capita amount of regional wealth, as the basis for allocating grants, should be calculated without taking into account natural capital, since the distribution of the latter is extremely uneven among the regions of the Russian Federation. For this reason, the authorities should not be encouraged for the fact that the region has a high supply of natural capital. While it is acceptable to allocate grants among the regions, given the advances in terms of availability of physical capital and human capital as the unity of economic space of Russia allows free movement of money capital and labor, and the task of authorities is to ensure acceptable conditions for the use of these resources.

The size of the grant in the first category for the subject of the Russian Federation we propose to determine by the formula

$$
D 1=D 1 \times W 1 i,
$$

where $W 1_{i}$ is the share of the $i$-th region among regions with per capita capital (physical and human) above the national average.

$$
W 1_{i}=\frac{\left(C_{i}^{+}-C\right) \times H_{i}}{\sum_{i=1}^{m}\left(C_{i}^{+}-C\right) \times H_{i}},
$$

where $C_{i}^{+}$is the per capita amount of capital (physical and human) in the $i$-th region, where this figure is above the national average; $C$ is average per capita amount of capital; $H_{i}$ is the number of permanent population in the $i$-th region at the end of the reporting period; $m$ is number of regions with a per capita amount of capital (physical and human) above average.

Thus, the amount of the grant in the first category is directly affected by two factors: 1) the positive deviation of the per capita capital in the region from the national average; 2 ) the number of permanent population in the region.

An example of calculating grants for the achieved per capita level of regional wealth in terms of the amount of physical capital and human capital is presented in table 2 .

However, as shown above, an increase in physical capital and human capital can occur at the expense of a decrease in natural capital. In this regard, the distribution of grants in the second and third categories is provided only between those regions that have achieved an increase in the total regional wealth.

The use of different bases (absolute growth and relative growth) is caused by the fact that the subjects of the Russian Federation differ significantly in population, size and structure of regional wealth. Regions differ markedly in their ability to increase regional wealth. One part of the regions can achieve success in increasing the absolute value of regional wealth (large regions), while the other part can differ in relative growth rates (small regions). The wealth of regions is an integral part of national wealth. Therefore, based on national interests, it is important to equally encourage the absolute and relative growth of regional

\begin{tabular}{|c|c|c|c|c|c|c|c|}
\hline \multirow{2}{*}{ Region } & \multirow{2}{*}{$\begin{array}{l}\text { Permanent } \\
\text { population of } \\
\text { the region, } \\
\text { million people }\end{array}$} & \multirow{2}{*}{$\begin{array}{l}\text { Physical capital, } \\
\text { RUB trillion }\end{array}$} & \multirow{2}{*}{$\begin{array}{l}\text { Human capital, } \\
\text { RUB trillion }\end{array}$} & \multirow{2}{*}{$\begin{array}{l}\text { Per capita size } \\
\text { of physical and } \\
\text { human capital, } \\
\text { RUB million }\end{array}$} & \multicolumn{3}{|c|}{$\begin{array}{c}\text { Calculation of the region's share and the grant amount } \\
\text { for the first category under the Fund } D 1=80 \text { RUB } \\
\text { million }\end{array}$} \\
\hline & & & & & $\left(C_{i}^{+}-C\right) \times H_{i}$ & $W_{i}$ & $D 1_{i}$ \\
\hline 1 & 10.0 & 3.0 & 27.0 & 3.0 & & & \\
\hline
\end{tabular}
wealth.

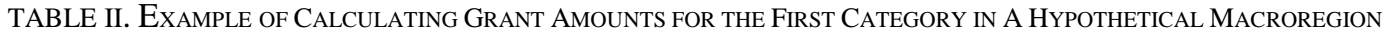




\begin{tabular}{|c|c|c|c|c|c|c|c|}
\hline 2 & 4.0 & 2.0 & 13.0 & $C_{1}^{+}=3.75$ & 1.82 & 0.62 & 49.6 \\
\hline 3 & 2.0 & 1.0 & 6.0 & $C_{2}^{+}=3.5$ & 0.41 & 0.14 & 11.2 \\
\hline 4 & 1.0 & 0.5 & 3.5 & $C_{3}^{+}=4.0$ & 0.71 & 0.24 & 19.2 \\
\hline Subtotal & 17.0 & 6.5 & 49.5 & & 2.94 & 1.00 & 80.0 \\
\hline On average & & & & $C=3.29$ & & & \\
\hline
\end{tabular}

A grantee for a positive absolute increase in regional wealth is any subject of the Russian Federation in which there was a positive increase in regional wealth during the reporting period. We propose to determine the size of the grant in the second category for a subject of the Russian Federation using the formula

$$
D 2_{i}=D 2 \times W 2_{i},
$$

where $W 2_{i}$ is the share of the $\boldsymbol{i}$-th region among regions with a positive absolute increase in regional wealth.

$$
W 2_{i}=\Delta A_{i} / \sum_{i=1}^{n} \Delta A_{i},
$$

where $\Delta A_{i}$ is absolute positive growth of regional wealth in the $i$-th region during the reporting period; $n$ - the number of regions with absolute positive growth of regional wealth during the reporting period.

A similar approach should be used to determine grants for the third category:

$$
D 3_{i}=D 3 \times W 3_{i},
$$

where $W 3_{i}$ is the share of the $i$-th region among regions with a positive relative increase in regional wealth.

$$
W 3_{i}=\Delta R_{i} / \sum_{i=1}^{n} \Delta R_{i},
$$

where $\Delta R_{i}$ is relative positive growth of regional wealth in the $i$-th region during the reporting period; $n$ - the number of regions with relative positive growth of regional wealth during the reporting period.

\section{CONCLUSION}

When assessing regional wealth in order to regulate spatial development, one should proceed from the following provisions. First, it is not possible to fully assess regional wealth for a number of reasons. Therefore, the indicator of regional wealth will always be a collection of only those components that are available for measurement. Secondly, the most important area of assessing regional wealth is to measure the dynamics of change in the integral indicator and its components with the possibility of interregional comparisons. Hence, the methodology for assessing regional wealth should ensure the comparability of results in time and space (between regions). Third, an objective conclusion about the effectiveness of public power can be drawn from data on regional wealth only if the public power has the appropriate regulatory instruments, and the conditions for the formation and use of regional wealth are within the sphere of power competences.

The prospects for research on measuring regional wealth are determined primarily by the needs of the Federal authorities responsible for regional development. Unfortunately, sometimes these needs arise due to force majeure, as shown in [18]. In recent years, a significant amount of work has been carried out in the Russian Federation to assess the cadastral value of land for various purposes. State statistical agencies plan to expand the list of surveyed components of national wealth in terms of natural capital. In parallel, it is necessary to conduct research to create a methodological apparatus that allows you to aggregate the components of regional wealth on a scientific basis.

\section{REFERENCES}

[1] P.A. Minakir, A.N. Demyanenko, The Economic Space of Modern Russia and the Approaches to Its Study (Part I), Regionalistics, 1, 2017, pp. 5-14.

[2] The changing wealth of nations 2018: Building a sustainable future, Ed. by Lange G.-M., Wodon Q., Carey K., Wash.: World Bank group, 2018, 233 p

[3] M.B. Ledeneva, "Growth in national wealth as an alternative to gross domestic product", Economic analysis: theory and practice, 21, 2012, pp. 10-18.

[4] V.V. Pechatkin, "Tools of the assessment of regional wealth and possibility of its use in practice of territorial administration", Property Relations in the Russian Federation, 2 (2014), pp. 55-61.

[5] I.S. Bukina, A.V. Odintsova, P.A. Orekhovsky, "Prosperity of Russian regions and efficiency of state governance", The Bulletin of the Institute of Economics of the Russian Academy of Sciences, 4, 2020, pp. 89-112.

[6] Decree of the President of the Russian Federation of November 14, 2017 No. 548 "On the assessment of the effectiveness of the executive authorities of the constituent entities of the Russian Federation, Collection of legislation of the Russian Federation, 47, 2017, Retrieved from http://www.szrf.ru/szrf/doc.phtml?nb=100\&issid=1002017047 $000 \&$ docid $=125 /$ (accessed 10.09.2020).

[7] Decree of the President of the Russian Federation of April 25, 2019 No. 193 "On the assessment of the effectiveness of the activities of senior officials (heads of the supreme executive bodies of state power) of the constituent entities of the Russian Federation and the activities of executive bodies of the constituent entities of the Russian Federation, Collection of legislation of the Russian Federation, 17, 2019, Retrieved from

http://www.szrf.ru/szrf/doc.phtml?nb=100\&issid=1002019017000\&d ocid=52/(accessed 10.09.2020).

[8] N.A. Latushko, "Assessment and measurement of the structure of the national wealth of the region: methodical approaches", Russian economic online journal, 4, 2018, pp. 67.

[9] O.G. Vasilyeva, "Natural resources: how to measure them in 'resource curse' studies", Spatial economics, 4, 2018, pp. 67-91.

[10] N.S. Smurova, "Assessment of the region's wealth in the regional spatial development management system", Innovations in Agricultural Complex: problems and perspectives, 3, 2020, pp. 181-186.

[11] O.A. Logvinenko, V.E. Strovskiy, "Natural resources as part of national wealth", News of the Ural State Mining University, 2, 2019, 126-133.

[12] L.V. Shamray-Kurbatova, M.V. Ledeneva, "Regional national wealth of the Volgograd region: essence, development trends and strategic 
directions of growth: monograph", Volgograd Scientific Publishing House, Volgograd, 2017.

[13] M.R. Tsibulnikova, "Role of natural capital for sustainable development of a region", Moscow University Bulletin. Series 5, Geography, 3, 2020, pp. 53-62.

[14] V.L. Anichin, Yu.Yu. Vashcheykina, N.S. Smurova, "Human capital as a system element of regional wealth, Innovations in Agricultural Complex: problems and perspectives", 4, 2018, pp. 49-59.

[15] V.V. Samoylenko, "Fishery rent and value of aquatic bioresources", Russian Journal of Marine Biology, 1, 2020, pp. 229-242.

[16] D.A. Alekseev, T.V. Sorokina, "The meaning of discounting procedure", Bulletin of Baikal State University. 6, 2016, pp. 972-979.

[17] N.S. Smurova, "Regional wealth as a result of the development of the regional socio-economic system", Proceedings of the International Conference on Basic and applied research in Economics and Finance, Central Russian Institute of management, Orel, 2019, pp. 310-326.

[18] R. Yamaguchi, M. Sato, K. Ueta, "Measuring regional wealth and assessing sustainable development: an application to a disaster-torn region in Japan”, Social Indicators Research, 129(1), 2016, pp. 365389 . 